\title{
Deriving inherent optical properties and associated inversion-uncertainties in the Dutch Lakes
}

\author{
M. S. Salama ${ }^{1}$, A. Dekker ${ }^{2}$, Z. Su ${ }^{1}$, C. M. Mannaerts ${ }^{1}$, and W. Verhoef ${ }^{1,3}$ \\ ${ }^{1}$ International Institute for Geo-Information Science and Earth Observation, Enschede, The Netherlands \\ ${ }^{2}$ Commonwealth Scientific and Industrial Research Organisation, Australia \\ ${ }^{3}$ The National Aerospace Laboratory NLR, Emmeloord, The Netherlands
}

Received: 13 February 2009 - Published in Hydrol. Earth Syst. Sci. Discuss.: 9 March 2009

Revised: 24 June 2009 - Accepted: 1 July 2009 - Published: 13 July 2009

\begin{abstract}
Remote sensing of water quality in inland waters requires reliable retrieval algorithms, accurate atmospheric correction and consistent method for uncertainty estimation. In this paper, the GSM semi-analytical inversion model is modified for inland waters to derive inherent optical properties (IOPs) and their spectral dependencies from air and space borne data. The modified model was validated using two data sets from the Veluwe and the Vecht Dutch lakes. For the Veluwe lakes, the model was able to derive a linear relationship between measured concentrations and estimated IOPs with $R^{2}$ values above 0.7 for chlorophyll- $a$ (Chl- $a$ ) and up to 0.9 for suspended particulate matters (SPM). In the Vecht lakes, the modified model derived accurate values of IOPs. The $R^{2}$ values were 0.89 for Chl $-a$ and up to 0.95 for SPM. The RMSE values were $0.93 \mathrm{mg} \mathrm{m}^{-3}$ and $0.56 \mathrm{~g} \mathrm{~m}^{-3}$ for Chl- $a$ and SPM respectively. Finally, the IOPs of the Veluwe lakes are derived from multi-spectral, ocean color and hyperspectral airborne data. Inversion-uncertainties of the derived IOPs were also estimated using a standard nonlinear regression technique. The study shows that inversionuncertainties of remote sensing derived IOPs are proportional to water turbidity.
\end{abstract}

\section{Introduction}

Lakes are important natural water resources yet they are seriously threatened by eutrophication, salinisation and heavy metal contamination. Increased sediment loads paly an important role in water quality of lakes since they relate total primary production to heavy metal and micro pollutants (Vos et al., 1998). Traditional measurements of water quality are costly, time-consuming and are limited in their spatial and

Correspondence to: M. S. Salama (salama@itc.nl) temporal coverage. Remote sensing data facilitate acquiring synoptic information of water quality at high temporal frequency. Monitoring of water quality using remote sensing, in conjunction with strategic in-situ sampling can play a crucial role in determining the current status of water quality conditions and helps anticipate, mitigate and even avoid future water catastrophes (GEOSS, 2007). Remote sensing of inland waters is quite challenging due to the complicated signals from turbid water, bottom reflectance and adjacent land surfaces. Moreover the empirical nature of the retrieval algorithms limits their application to a specific range of concentrations, area and season. Kallio et al. (2001) studied different algorithms to estimate chlorophyll- $a$ in lakes. These algorithms were empirical and estimated one variable using band-ratio of approximately $675 \mathrm{~nm}$ and $705 \mathrm{~nm}$ (Dekker et al., 1992; Gitelson et al., 1993). A generalized retrieval algorithm is, however, hindered by the large natural variability of inland waters (Shen et al., 2009). Significant efforts on improving the accuracy of air and space borne derived water quality parameters are therefore required for inland and near coastal waters. Many studies have used semi analytical models to derive water quality parameters in lakes (Hoogenboom et al., 1998; Gons et al., 2002). Semi-analytical model inversion has been shown promising for case 2 waters (Doerffer and Fischer, 1994; Kishino et al., 2005; Van der Woerd and Pasterkamp, 2008). These studies assumed, however, known spectral dependencies of dissolved matter and detritus absorption and sediment scattering. This was in order to limit the number of unknowns and reduce uncertainties (Lee and Carder, 2005). Values of these spectral shapes are related to the constituent's bio-geophysical composition and are not always known, any wrongly assumed spectral shape will lead to significant alteration of the derived inherent optical properties (IOPs). In this paper the GSM semi-analytical inversion model (Maritorena et al., 2002) is modified to derive the IOPs and their spectral dependencies. The method of Bates and Watts (1988) is used to estimate inversion-uncertainties

Published by Copernicus Publications on behalf of the European Geosciences Union. 
of the derived IOPs following previous researchers (Salama, 2003; Wang et al., 2005; Maritorena and Siegel, 2005).

\section{Method}

The total remote sensing reflectance received at the sensor level can be written as the sum of several components (Gordon, 1997):

$$
R s_{t}(\lambda)=R s_{\mathrm{r}}(\lambda)+R s_{\mathrm{a}}(\lambda)+T_{\mathrm{v}}(\lambda)\left\{R s_{\mathrm{sfc}}(\lambda)+R s_{\mathrm{W}}(\lambda)\right\}
$$

where $T_{\mathrm{V}}(\lambda)$ is the viewing diffuse transmittance from the water surface to the sensor. The subscript of the reflectance represents the contribution from air molecules $r$, aerosol $a$, surface $s f c$, and water $w$. The calculation of Rayleigh scattering of air molecules is well described in terms of geometry and pressure (Gordon et al., 1988a). Water surface reflectance can be estimated using statistical relationships and wind speed (Cox and Munk, 1954a,b). Gaseous transmittance can be calculated from ancillary data on ozone and water vapor content using transmittance models (Goody, 1964; Malkmus, 1967). Viewing diffuse transmittance is approximated following Gordon et al. (1983). Aerosol scattering can be evaluated from measured aerosol optical thickness and assumed aerosol type. This information about the atmospheric path reflectance facilitates the retrieval of the signal leaving the water body i.e. $R s_{\mathrm{W}}$. Water remote sensing reflectance $R s_{\mathrm{W}}(\lambda)$ can be related to the inherent optical properties (IOPs) of the water column as (GSM model: Maritorena et al., 2002):

$R s_{\mathrm{w}}(\lambda)=\frac{t}{n_{\mathrm{w}}^{2}} \sum_{i=1}^{2} g_{i}\left(\frac{b_{b}(\lambda)}{b_{b}(\lambda)+a(\lambda)}\right)^{i}$

where $g_{1}, g_{2}$ are subsurface expansion coefficients due to internal refraction, reflection and sun zenith; $t$ and $n_{\mathrm{w}}$ are the sea air transmission and water index of refraction, respectively. Their values are taken from literature (Gordon et al., 1988b; Maritorena et al., 2002; Lee, 2006). The parameters $b_{b}(\lambda)$ and $a(\lambda)$ are the bulk backscattering and absorption coefficients of the water column. Case II water is considered with three independently varying constituents, namely: chlorophyll- $a$ (Chl- $a$ ), detritus and dissolved organic matter (dg) and suspended particulate matter (SPM). The absorption and backscattering coefficients are modeled as being the sum of absorption and backscattering from all water constituents:

$$
a(\lambda)=a_{\mathrm{w}}(\lambda)+a_{\mathrm{ph}}(\lambda)+a_{\mathrm{dg}}(\lambda)
$$

$b_{b}(\lambda)=0.5 b_{\mathrm{w}}(\lambda)+\alpha b_{\mathrm{spm}}(\lambda)$

The absorption and scattering coefficients of water molecules, $a_{\mathrm{w}}$ and $b_{\mathrm{w}}$, were assumed constants. Their values were obtained from (Pop and Fry, 1997; Mobley, 1994), respectively.
The total absorption of phytoplankton pigments $a_{\mathrm{ph}}$ is approximated as (Lee et al., 1999):

$a_{\mathrm{ph}}(\lambda)=a_{0}(\lambda) a_{\mathrm{ph}}(0.44)+a_{1}(\lambda) a_{\mathrm{ph}}(0.44) \ln a_{\mathrm{ph}}(0.44)$

where $a_{0}(\lambda)$ and $a_{1}(\lambda)$ are empirical coefficients. The absorption effects of detritus and dissolved organic matter are combined due to the similar spectral signature (Maritorena et al., 2002) and approximated using the model (Bricaud et al., 1981):

$a_{\mathrm{dg}}(\lambda)=a_{\mathrm{dg}}(440) \exp [-s(\lambda-440)]$

where $s$ is an unknown spectral exponent. The scattering coefficient of SPM $b_{\mathrm{spm}}$ is parameterized as (Kopelevich, 1983):

$b_{\mathrm{spm}}(\lambda)=b_{\mathrm{spm}}(550)\left(\frac{550}{\lambda}\right)^{y}$

where $y$ is the unknown spectral shape parameter. The backscattering fraction $\alpha$ is estimated from the "San Diego harbor" scattering phase function (Petzold, 1977).

The inversion of the GSM model is adapted to derive five parameters in visible bands covering the wavelengths from $400 \mathrm{~nm}$ to $850 \mathrm{~nm}$. These parameters are called the set of IOPs and denoted as a vector iop:

iop $=\left[\begin{array}{c}a_{\mathrm{ph}}(440) \\ a_{\mathrm{dg}}(440) \\ b_{\mathrm{spm}}(550) \\ s \\ y\end{array}\right]$

The Levenberg-Marquardt Algorithm (LMA) is employed using a constrained nonlinear optimization (Press et al., 2002). The constraints are set such that they guarantee positive values of retrieved IOPs. Both parameters, concentration and absorption/(back)scattering coefficients, are denoted using the same abbreviation of the constituent itself i.e., dg, Chl- $a$, SPM.

\section{Materials}

\subsection{Field measurements and study areas}

This study will use two sets of field measurements covering in the Veluwe and the Vecht lakes in the Netherlands. The first set, contains water leaving reflectance and concentrations of suspended sediment and chlorophyll- $a$ at eight sites in the Wolderwijd and Veluwemeer, i.e. the Veluwe lakes, centered at $52^{\circ} 19^{\prime} 12.0^{\prime \prime} \mathrm{N}, 05^{\circ} 36^{\prime} 12.0^{\prime \prime} \mathrm{E}$. Field measurements of the Veluwe lakes were collected during the EAGLE 2006 campaign and reported in (Timmermans et al., 2007; Su et al., 2009). Table 1 shows the locations of these sites and measured concentrations of SPM and Chl- $a$ in the lab. Measured spectra of water leaving reflectance are shown in Fig. 1. 


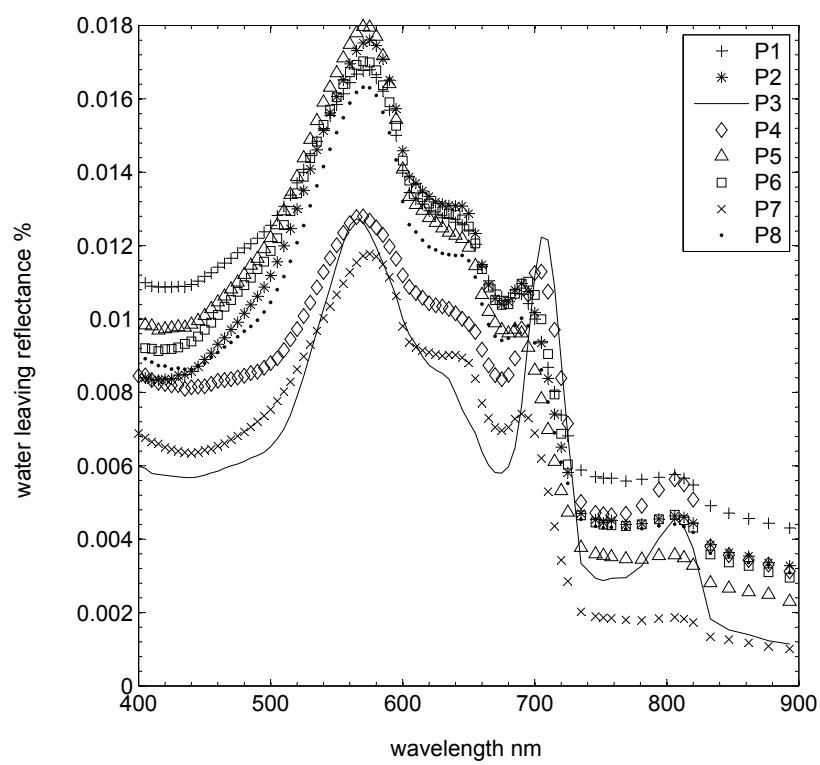

Fig. 1. Measured water leaving reflectance in the Veluwe lakes during the EAGLE 2006 campaign.

Table 1. Locations of the sampling sites and measured concentrations in the Veluwe lakes during the EAGLE 2006 campaign.

\begin{tabular}{|c|c|c|c|c|}
\hline site & Lat & Long & $S P M g^{-3}$ & Chl- $a \mathrm{mg} \mathrm{m}^{-3}$ \\
\hline P1 & 52.37481 & 5.63524 & 5.84 & 10.4 \\
\hline $\mathrm{P} 2$ & 52.38326 & 5.63874 & 4.47 & 6.8 \\
\hline P3 & 52.37735 & 5.65598 & 1.86 & 2.3 \\
\hline P4 & 52.37566 & 5.66849 & 3.04 & 5.7 \\
\hline P5 & 52.39295 & 5.65845 & 2.78 & 9.4 \\
\hline P6 & 52.38732 & 5.64361 & 3.96 & 6.2 \\
\hline P7 & 52.37570 & 5.62356 & 3.44 & 6.7 \\
\hline P8 & 52.36788 & 5.63584 & 0.93 & 4.2 \\
\hline
\end{tabular}

The second set consists of measured under-water irradiance reflectance, inherent optical properties and concentrations of water constituents at 20 sites in the Vecht lakes, centered at $52^{\circ} 10^{\prime} 9.0^{\prime \prime} \mathrm{N}, 05^{\circ} 10^{\prime} 15.0^{\prime \prime} \mathrm{E}$. Data on the optical and physical properties of the Vecht lakes were obtained from Dekker (1993) and Dekker et al. (1997).

\subsection{Remote sensing data set}

The EAGLE 2006 campaign was associated with hyperspectral airborne measurements from the Airborne Hyperspectral Spectrometer (AHS) (Fernández-Renau et al., 2005). MEdium Resolution Imaging Spectrometer (MERIS) and Advanced Space borne Thermal Emission and Reflection Radiometer (ASTER) observations were also available during the EAGLE 2006 campaign. Table 2 summarizes the used data sets in this work. For more details on data availabilities and specifications, the reader is encouraged to consult the
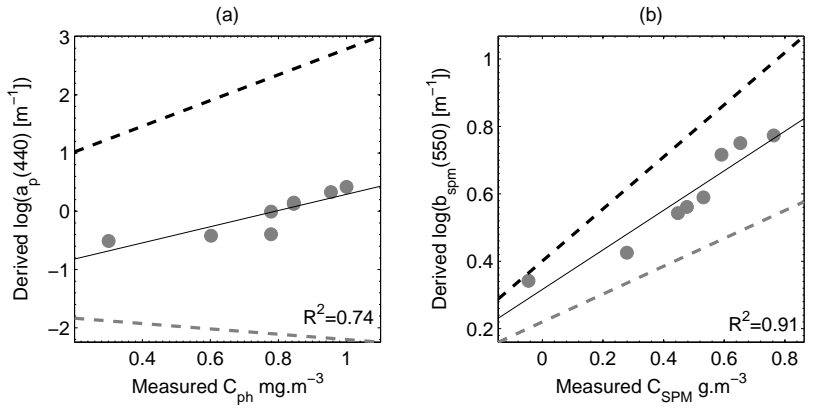

Fig. 2. Comparison between the derived IOPs and measured concentrations in the Veluwe lakes of (a): chlorophyll- $a$ and (b): SPM. The bold line is a linear regression through the data. The dashed lines denote the $95 \%$ confidence interval of the regression results. The $R^{2}$ values are for the data points.

EAGLE 2006 data acquisition reports (Timmermans et al., 2007; Su et al., 2009) and the works of Dekker (1993) and Dekker et al. (1997).

\section{Results}

\subsection{Model validation}

The modified inversion model is validated with in-situ measurements in the Veluwe and the Vecht lakes. Figure 2 shows the derived IOPs versus measured concentrations in the Veluwemeer and Wolderwijd, i.e. the Veluwe lakes. There is a strong linear relationship between derived IOPs and measured concentrations. The $R^{2}$ values of model-I regression (Laws, 1997) is about 0.74 and 0.9 for chlorophyll$a$ and SPM respectively. Following the Lambert-Beer law one can easily derive the specific inherent optical properties (SIOPs) of chlorophyll- $a$ and SPM, i.e. the amount of absorption/scattring per unit concentration. For demonstration, the regression line and the $95 \%$ confidence interval between the IOPs and corresponding concentrations are also shown in Fig. 2.

Figure 3 shows derived versus measured values of IOPs in the Vecht lakes. Four IOPs are shown: three absorption coefficients $a_{\mathrm{ph}}(440), a_{\mathrm{dg}}(440), a_{\mathrm{total}}(440)$ and one scattering coefficient $b_{\mathrm{spm}}$ (550). Model II regression (Laws, 1997) is used to evaluate the match between derived and measured values in Table 3 for log-transformed data. The derived IOPs are within acceptable accuracy, i.e. the $R^{2}$ is higher than 0.85 for the four derived IOPs. The derived scattering coefficient at $550 \mathrm{~nm}$ has the highest accuracy with RMSE value less than $0.56 \mathrm{~g} \mathrm{~m}^{-3}$ and $R^{2} \sim 0.95$. The uncertainties in the retrieved absorption coefficients are large, particularly the value of $a_{\mathrm{ph}}(440)$ with a RMSE value $\sim 0.95 \mathrm{mg} \mathrm{m}^{-3}$. 
Table 2. Summary of the data sets used in this study.

\begin{tabular}{lllr}
\hline Acquisition & Type & Description & Date \\
\hline Space borne & ocean color, MERIS & FR level L1b & $08-06-2006$ \\
Space borne & multispectral, ASTER & level L1b & $08-06-2006$ \\
Airborne & hyperspectral, AHS & Level L1b & $13-06-2006$ \\
Field measurements & above water radiance and water samples & Veluwe lakes & $04-07-2006$ \\
Field measurements & above/under water radiance, IOPs and water samples & Vecht lakes & $1993-1997$ \\
IOCCG & simulated data set & spectra and IOPs & 2006 \\
\hline
\end{tabular}
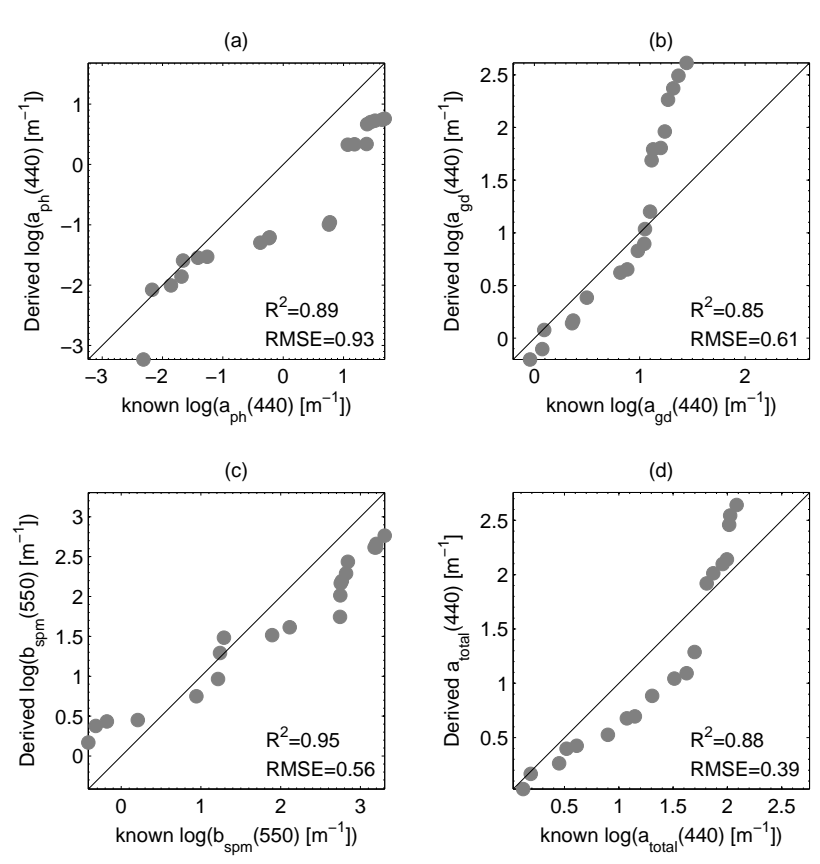

Fig. 3. Comparison between the derived and measured values in the Vecht lakes of (a): chlorophyll- $a$ absorption coefficient at $440 \mathrm{~nm}$, (b): dg absorption coefficient at $440 \mathrm{~nm}$, (c): SPM scattering coefficient at $550 \mathrm{~nm}$ and (d): total absorption coefficient at $440 \mathrm{~nm}$. The bold line denote the $1: 1$ line.

\subsection{Intercomparison of remotely sensed products}

Available images during the EAGLE 2006 campaign are geo-referenced and converted to at-sensor-reflectance. Atmospheric path correction is then preformed using the radiative transfer method of Vermote et al. (1997). Gaseous transmittances of ozone, oxygen, carbon dioxide, methane and nitrous oxide are assumed constant over the study region. Measured values of aerosol optical thickness during the the EAGLE 2006 campaign are used to run the computation, assuming an urban aerosol. The adjacency effects from the surrounding lands was accounted for in the computation. The IOPs are derived using the constrained LMA. This method is applied on MERIS and AHS spectra, while another method is used for ASTER image. The
Table 3. RMSE and type-II regression parameters between measured and derived IOPs in the Vecht Lakes. $n$ is the number of data points.

\begin{tabular}{lccccr}
\hline Parameter & $n$ & Intercept & Slope & $R^{2}$ & RMSE \\
\hline$a_{\mathrm{ph}}(440)$ & 20 & -0.73 & 0.83 & 0.89 & 0.93 \\
$a_{\mathrm{dg}}(440)$ & 20 & -0.58 & 1.98 & 0.85 & 0.61 \\
$a(440)$ & 20 & -0.54 & 1.40 & 0.88 & 0.39 \\
$b_{\text {spm }}(550)$ & 20 & 0.37 & 0.67 & 0.95 & 0.56 \\
\hline
\end{tabular}

spectral characteristics of ASTER constrain the application of such nonlinear fit method. There are several methods that were successfully applied to ASTER and other sensors with few visible bands (Kishino et al., 2005; Salama et al., 2004). For ASTER's two visible bands, the matrix inversion method (Hoge and Lyon, 1996) was applied assuming known value of $a_{\mathrm{dg}}(440)=0.25 \mathrm{~m}^{-1}$. In consequence only two variables were retrieved from ASTER image, namely SPM scattering and Chl- $a$ absorption coefficients. An intercomparison between retrieved values of SPM scattering and Chl- $a$ and dg absorptions are shown in Fig. 4 for two cross sections over the Veluwemeer (start 52.38307, 5.63710, end 52.3681, 5.65516) and the Wolderwijd (start 52.34515, 5.60731, end $52.3579,5.59198)$. There is a very good match between the products of AHS and MERIS while retrieved values from ASTER are patchy and don't correspond to derived IOPs from other sensors.

\subsection{Inversion-uncertainties of AHS derived IOPs}

The nonlinear regression method of Bates and Watts (1988) is used to estimate the inversion-uncertainties of derived IOPs. However, this approach is only applicable with nonlinear optimization techniques. Nonlinear optimization is used with AHS and MERIS but not with ASTER. To derive the uncertainty of ASTER products, other methods are needed. However we will limit the discussion to the inversion-uncertainty maps associated with AHS products. The standard deviation (STD) at $95 \%$ of confidence will be used as quantitative measure of uncertainty. The uncertainties of AHS derived IOPs are shown in Fig. 5. The 

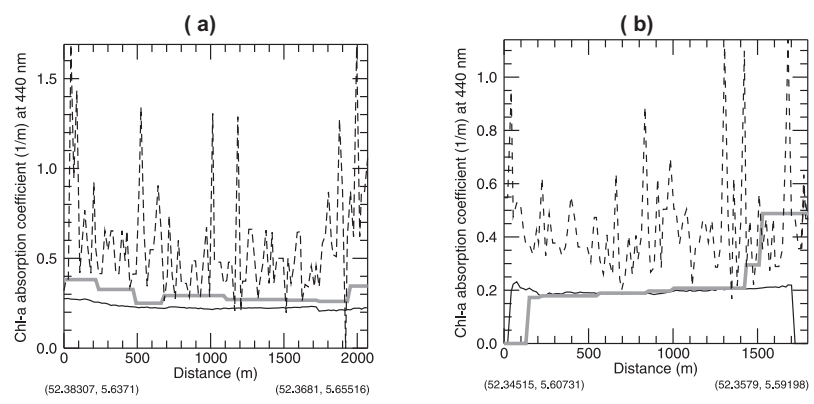

(c)
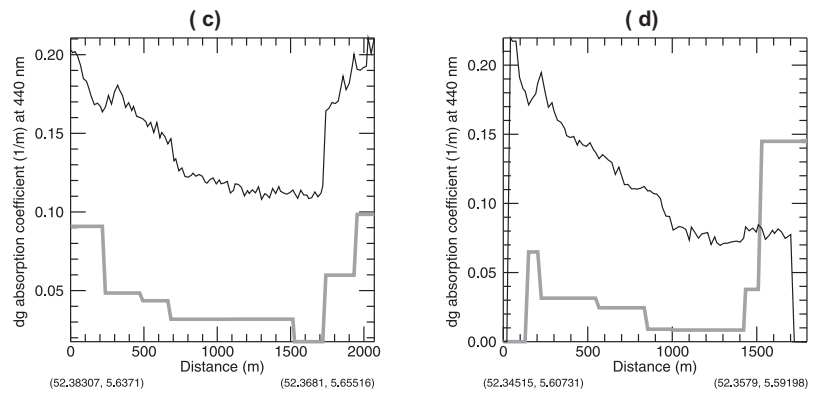

(e)
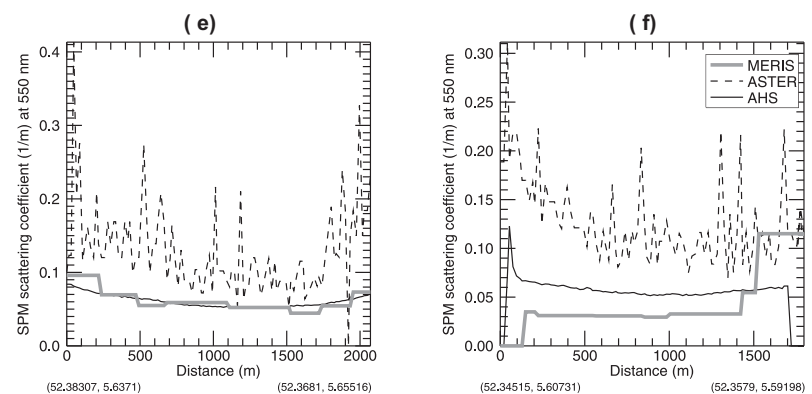

Fig. 4. Intercomparison of IOPs derived from MERIS (gray thickline), ASTER (dashed line) and AHS (black thin-line) for a crosssection at the Veluwemeer (Fig. a, c, e) and a cross-section at the Wolderwijd (Fig. b, d, f). The derived IOPs are: Chl- $a$ (a and b), dg (c and d) and SPM (e and f).

inversion-uncertainty maps of IOPs have similar spatial variations and their values increase proportionally to water turbidity as shown in Fig. 6.

\section{Discussion}

\subsection{Validation}

For the Veluwe lakes, the model was able to derive the linear relationship between measured concentrations and estimated IOPs. The $R^{2}$ values of model-I regression were above 0.7 for chlorophyll- $a$ and up to 0.9 for SPM. The SIOPs values of the Veluwe lakes are not documented yet. Therefore, using reported values of SIOPs for other Dutch lakes, e.g. (Hakvoort et al., 2002), will lead to significant errors in the derived concentrations.
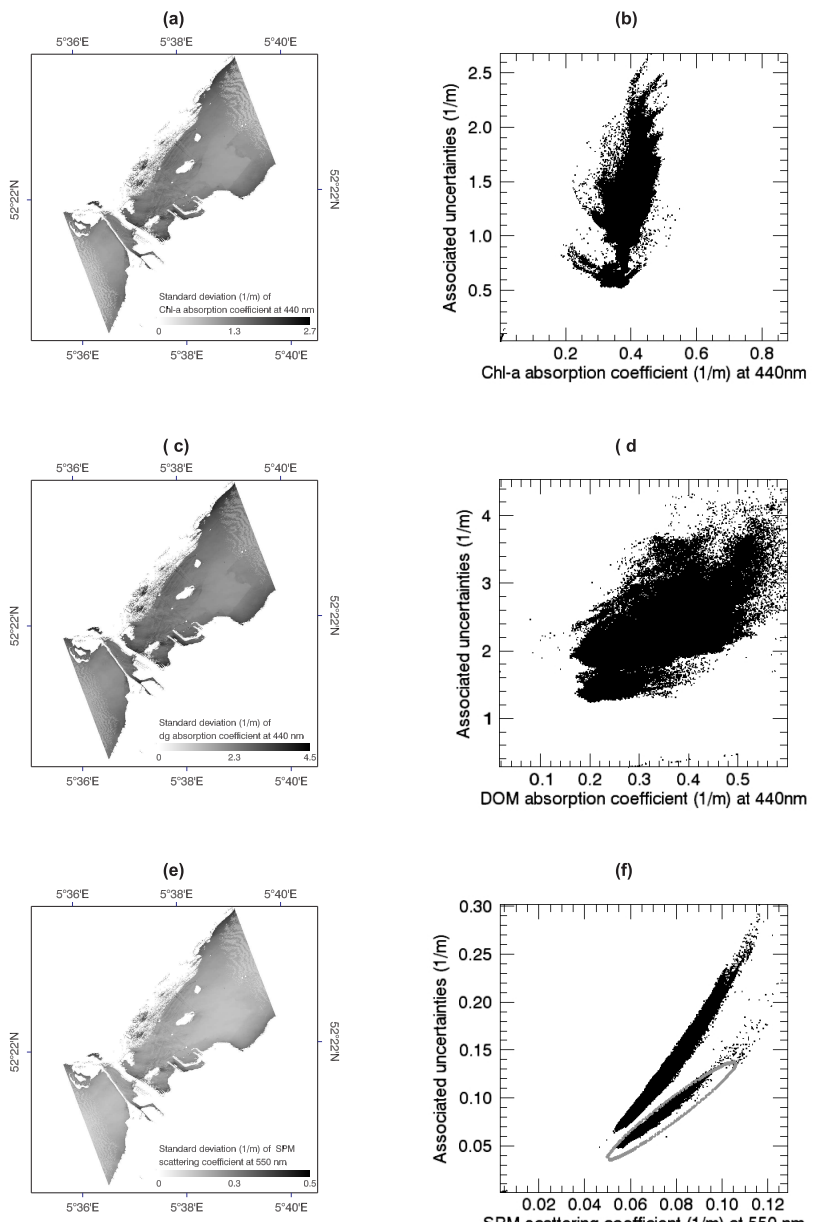

(f)

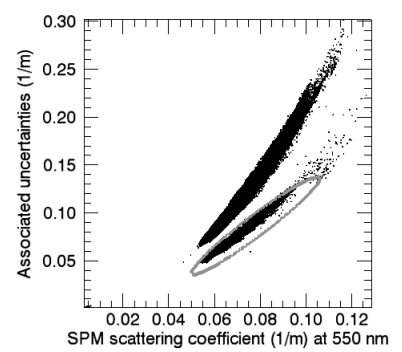

Fig. 5. The standard deviation (STD) maps for each of the retrieved IOPs from AHS data set of (a): Chl- $a,(\mathbf{c})$ : $\mathrm{dg}$ and (e): SPM. Right panels (Fig. b, d, f) illustrate the scatter plot between standard deviations values on the Y-axis and the corresponding IOPs values on the $\mathrm{X}$-axis.

In the Vecht lakes, the modified model succeeded in deriving the IOPs with $R^{2}$ higher than 0.85 and $100 \%$ of valid retrievals. While, the RMSE values of the retrieved absorption coefficients were large, particularly for Chl- $a$, the RMSE value of SPM were less than $0.6 \mathrm{~g} \mathrm{~m}^{-3}$ with $R^{2}=0.95$. The high accuracy of derived SPM scattering coefficient is due to including the red and Near Infra Red (NIR) bands in the inversion. At this part of the spectrum, water absorption and SPM backscattering are the major contributors to the observed reflectance. For example, at wavelength $780 \mathrm{~nm}$ the water absorption is invariant to water temperature (Hakvoort, 1994) and thus the reflectance will linearly respond to any increase in SPM concentration. This linearity between reflectance and SPM backscattering at the red and NIR region will stabilize the inversion and reduce the uncertainty.

The modified GSM model-inversion performed well for moderate values of IOPs: up to $0.28 \mathrm{~m}^{-1}, 3 \mathrm{~m}^{-1}$ and $4 \mathrm{~m}^{-1}$ 

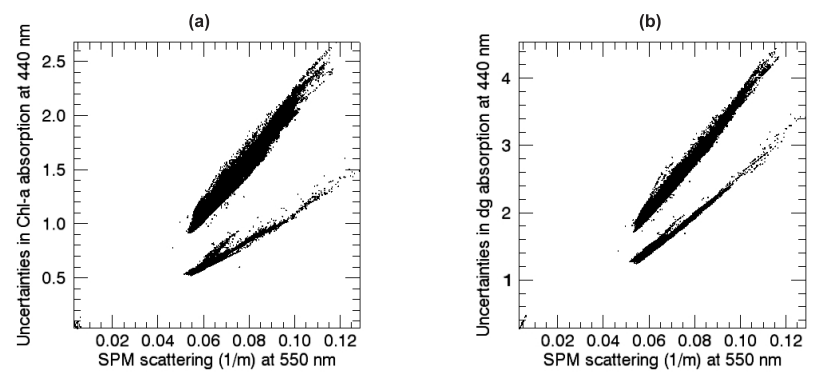

Fig. 6. The standard deviation (STD) of derived: (a) Chl- $a$ and (b) dg absorption coefficients as function of the estimated values of SPM scattering.

for $a_{\mathrm{ph}}(440), a_{\mathrm{dg}}(440)$ and $b_{\mathrm{spm}}(550)$ respectively. However, the modified model could not derive accurate IOPs values when the scattering and absorption coefficients are above $20 \mathrm{~m}^{-1}$ and $10 \mathrm{~m}^{-1}$ respectively. We think that model parameterizations in Eq. (5), Eq. (6) and Eq. (7) are not adequate for inland waters with extreme values of absorption and scattering. Each of these parameterizations poses one limitation on the model: (i) Eq. (5) ignores the different phytoplankton species that may co-exist in inland water; (ii) Eq. (5) also ignores the great variability of Chl- $a$ absorption as measured in nature (Bricaud et al., 1995, 1998; Carder et al., 1999); (iii) Eq. (6) combines the absorption effect of detritus and CDOM in one spectral shape and magnitude; (iv) the overlapped absorption spectra of CDOM, detritus and Chl- $a$ at $440 \mathrm{~nm}$ will also encumber their retrievals. For instance, Fig. $3 \mathrm{a}$ and $\mathrm{b}$ show that the trend of derived Chl- $a$ absorption, w.r.t. actual values, is inversely correlated to that of derived absorption of CDOM and detritus, i.e. underestimated values of $a_{\mathrm{ph}}(440)$ are associated with overestimated values of $a_{\mathrm{dg}}(440)$ and vice versa. The effects of over/under estimations will compensate each other when the total absorption coefficient is evaluated, as shown in Fig. 3d.

The consistency of the adapted inversion, with respect to the original GSM model, is analyzed using the same data set (Lee, 2006, IOCCG data set). Figure 7 shows derived versus known values of IOPs using the IOCCG data set. The statistical parameters of model II regression (Laws, 1997) were also used to evaluate the match between derived and known values as shown in Table 4. The modified GSM succeeded in deriving the IOPs with $R^{2}$ higher than 0.9 and $100 \%$ of valid retrievals from the IOCCG data set, for comparison one may consult (Lee, 2006, p. 83-84). Moreover, the validation results of IOCCG data set are consistent with the validation results of in-situ measured parameters in the Vecht lakes: (i) derived $a_{\mathrm{ph}}(440)$ has the highest RMSE; (ii) derived $a_{\mathrm{ph}}(440)$ and $a_{\mathrm{dg}}(440)$ are opposite to each other in their trends; (iii) the opposite trend of $a_{\mathrm{ph}}(440)$ and $a_{\mathrm{dg}}(440)$ is compensated in the $a_{\text {tot }}(440)$; (iv) the accuracy of SPM scattering is the highest among other derived IOPs.
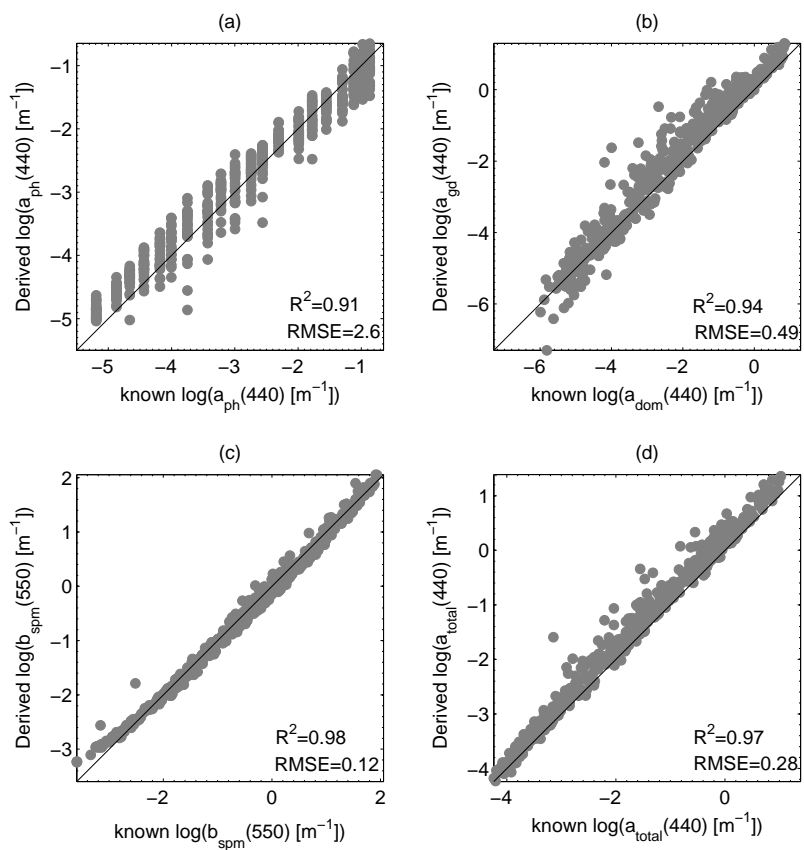

Fig. 7. Comparison between the derived and simulated IOCCG values of (a): chlorophyll- $a$ absorption coefficient at $440 \mathrm{~nm}$, (b): $\mathrm{dg}$ absorption coefficient at $440 \mathrm{~nm}$, (c): SPM scattering coefficient at $550 \mathrm{~nm}$ and (d): total absorption coefficient at $440 \mathrm{~nm}$. The bold line denote the 1:1 line.

Table 4. RMSE and type-II regression parameters between known and derived values form the IOCCG data set. $n$ is the number of data points.

\begin{tabular}{lcrccc}
\hline Parameter & $n$ & Intercept & Slope & $R^{2}$ & RMSE \\
\hline$a_{\mathrm{ph}}(440)$ & 500 & 0.0039 & 0.92 & 0.91 & 1.15 \\
$a_{\mathrm{dg}}(440)$ & 500 & 0.0097 & 1.35 & 0.94 & 0.21 \\
$a(440)$ & 500 & -0.0041 & 1.27 & 0.97 & 0.12 \\
$b_{\text {spm }}(550)$ & 500 & -0.0515 & 1.02 & 0.98 & 0.05 \\
\hline
\end{tabular}

However the RMSE values between derived and measured data in the Vecht lakes are larger by three folds, for the absorption, to an order of magnitude for the scattering. This increase in RMSE values is related to the optical-complexity of inland waters and emphasizes our previous findings that new parameterizations should be adapted for, case 2, inland waters.

\subsection{Remotely sensed products}

MERIS case 2 processors are well established methods for atmospheric correction and derivation of IOPs from MERIS images in case 2 waters (Doerffer and Schiller, 2007; Schroeder et al., 2007). The same atmospheric correction procedure is applied on ASTER, AHS and MERIS to avoid possible bias and errors that may arise when using different 
atmospheric correction methods. The derived values of SPM scattering and Chl- $a$ absorption from ASTER are patchy and did not reflect the spatial variability as observed from MERIS and AHS. This can be attributed to the retrieval method applied on ASTER. The inversion of ASTER was based on matrix inversion of Eq. (2) in two bands with a constant value of $\mathrm{dg}$ absorption coefficient at $440 \mathrm{~nm}\left(=0.25 \mathrm{~m}^{-1}\right)$. On the other hand, the retrieval method of MERIS and AHS was based on nonlinear optimization for five variables in all visible bands i.e. 15 for MERIS and 16 for AHS. There is a very good match in the retrieved values of SPM scattering at the Veluwemeer (Fig. 4e) and Chl- $a$ absorptions at the Wolderwijd (Fig. 4b). However, slight overestimation of Chl- $a$ absorption and underestimation of SPM scattering coefficients with-respect-to (w.r.t.) AHS can be observed in Fig. 4a and Fig. 4f respectively. The values of dg absorption coefficient are generally overestimated w.r.t. AHS retrieved values, with the same spatial variation, however. The differences between MERIS and AHS results may be attributed to imperfect atmospheric correction and inappropriate spectral coverage of AHS for Chl- $a$ retrieval. On the one hand, the longer atmospheric path of MERIS w.r.t. AHS signals increases the contributions of aerosol scattering and illumination-viewing variations to the top of atmosphere (TOA) reflectance. It is also noted that AHS spectral range does not cover chlorophyll- $a$ absorption feature centered at $440 \mathrm{~nm}$. This absorption feature is of quite importance for reliable estimation of Chl- $a$ and dg absorption coefficients. The combined effects of the longer atmospheric path and the absence of $440 \mathrm{~nm}$ absorption feature will increases the uncertainties on the retrieved values of dg and Chl- $a$. A major limitation in this work is that air and space borne images were not concurrent with field measurements such that independent validation of remotely sensed products was not possible.

\subsection{Inversion-uncertainties}

The method of Bates and Watts (1988) was used to estimate the uncertainties of derived IOPs. However, this approach is adequate as long as model inversion has a well conditioned Jacobian matrix of the minimum cost function. It reflects how well the model can fit the observation but not how well the derived parameters fit the measured values. The estimated uncertainties (Fig. 5), therefore do not reflect the actual uncertainties which are presented in Table 4 as RMSE values. This total uncertainty of derived values can roughly be assigned to three main causes: residuals, numerical and physical sources. Residuals are errors originated from sensor noise and imperfect atmospheric correction or any other correction. The numerical part is related to the used numeric technique in the inversion. The physical uncertainty is caused by two distinctive sources: bio-optical model approximations and the intrinsic relation between apparent and inherent optical properties of the water column which causes reflectance ambiguity. The later is an inherent problem to remote sensing of water quality (Sydor et al., 2004). In this sense, mainly model approximation and inversion accuracy were quantified in Fig. 5. Figure 5 shows that there are weak relationships between derived values of absorption coefficients and associated uncertainties. This is not the case for the scattering where a clear relationship can be observed (Fig. 5c). The error increases exponentially with the magnitude of derived values. Actually, the uncertainty of all IOPs increase proportionally to water turbidity (Fig. 6). Therefore, larger errors are expected in turbid waters. Two water types can be distinguished from the right panels of Fig. 5 and Fig. 6. The pixels within the gray region have STD values less than the value of the corresponding IOPs. These pixels correspond to relatively smaller range of derived IOPs. The remaining pixels, which form the majority, have their STD values higher than the retrieved values of IOPs, i.e. uncertainty is more than $100 \%$. This grouping is caused by the large inversion errors in case 2 waters with large values of scattering and absorption. This was already predicted during model validation in the Vecht lakes, Fig. 3). This kind of comparison between derived values and their uncertainties has been found useful for resolving the sub-pixel variability of earth observation hydrological products (Van der Velde et al., 2008).

\section{Conclusions}

In this paper the GSM model was modified to retrieve five parameters: three IOPs and two spectral exponents. The method is applied on MERIS and AHS and validated using measured and IOCCG data sets. From the presented work in this paper we conclude the followings:

- The proposed modification improved the performance of the GSM model for simulated data and derived reliable results for measured data.

- The red and NIR bands, with sufficient signal-to-noise ratio, are necessary for remote sensing of inland water. They improve the accuracy of derived IOPs.

- Improved parametrization of IOPs is needed for inland waters. The improvement should account for: (i) different phytoplankton species; (ii) the absorption of SPM as linked to the concentration.

- Inversion-uncertainty of derived IOPs is proportional to water turbidity and is not representative of our confidence about the derived products from remote sensing data. Therefore a better measure of uncertainty should be investigated. 
Acknowledgements. The authors would like to thank the European Space Agency (ESA) for supporting this research and supplying MERIS data, the Instituto Nacional de Técnica Aeroespacial (INTA) for providing high quality hyperspectral dataset and technical assistance, the National Aeronautics and Space Administration (NASA) for providing ASTER data, the EAGLE 2006 team for collecting and archiving in-situ measurements. The financial support of ESA, arrangement No. 20239/06/I-LG, is gratefully acknowledged. Emmanuel Boss, anonymous reviewer and Jun Wen are gratefully acknowledged for revising the manuscript and improving on its quality.

Edited by: J. Wen

\section{References}

Bates, D. and Watts, D.: Nonlinear regression analysis and its applications, John Wiley and Sons, NY, 365 pp., 1988.

Bricaud, A., Morel, A., and Prieur, L.: Absorption by dissolved organic-matter of the sea (yellow substance) in the UV and visible domains, Limnol. Oceanogr., 26, 43-53, 1981.

Bricaud, A., Babin, M., Morel, A., and Claustre, H.: Variability in the chlorophyll-specific absorption coefficients of naturnal phytoplankton: Analysis and parameterization, J. Geophys. Res., 100, 13321-13332, 1995.

Bricaud, A., Morel, A., Babin, M., Allali, K., and Claustre, H.: Variations of light absorption by suspended particles with chlorophyll a concentration in oceanic (case 1) waters: Analysis and implications for bio-optical models, J. Geophys. Res., 103(C13), 31033-31044, 1998.

Carder, K., Chen, F., Lee, Z., Hawes, S., and Kamykowski, D.: Semianalytical Moderate-Resolution Imaging Spectrometer algorithms for chlorophyll-a and absorption with bio-optical domains based on nitrate-depletion temperature, J. Geophys. Res., 104, 5403-5421, 1999.

Cox, C. and Munk, W.: Measurements of the roughness of the sea surface from photographs of the sun glitter, J. Opt. Soc. Am., 44, 838-850, 1954a.

Cox, C. and Munk, W.: Statistics of the sea surface derived from sun glitter, J. Mar. Res., 13, 198-227, 1954b.

Dekker, A.: Detection of optical water quality parameters for eutrophic waters by high resolution remote sensing, $\mathrm{Ph} . \mathrm{D}$. thesis, Vrije Universiteit, Amsterdam, 1993.

Dekker, A., Malthus, T., Wijnen, M., and Seyhan, E.: Remote sensing as a tool for assessing water quality in Loosdrecht Lakes, Hydrobiologia, 233, 137-159, 1992.

Dekker, A., Hoogenboom, H., Goddijn, L., Malthus, T.: The relationship between inherent optical properties and reflectance spectra in turbid inland waters, Remote Sens. Reviews, 15, 5974, 1997.

Doerffer, R. and Fischer, J.: Concentration of chlorophyll, suspended matter, and gelbstoff in case II waters derived from satellite coastal zone color scanner with inverse methods, J. Geophys. Res., 99, 7457-7466, 1994.

Doerffer, R. and Schiller, H.: The MERIS cas 2 water algorithm, Int. J. Remote Sens., 28, 3/4, 517-535, 2007.

Fernández-Renau, A., Gómez, J. A., and De Miguel, E.: The INTAAHS system, in: SPIE proceeding of Sensors, Systems and NextGeneration Satellites IX, Vol. 5978, 471-478, 2005.
GEOSS: GEO Inland and nearshore coastal water quality remote sensing, in: GEOSS group on earth observation, edited by: Bauer, M., Dekker, A., DiGiacomo, P., Greb, S., Gitelson, A., Herlevi, A., and Kutser, T., GEO, 2007.

Gitelson, A., Garbuzov, G., Szilagyi, F., Mittenzwey, K. H., Karnieli, A., and Kaiser, A.: Quantitative remote sensing methods for real-time monitoring of inland waters quality, Int. J. Remote Sens., 14, 1269-1295, 1993.

Gons, H., Rijkeboer, M., and Ruddick, K.: A chlorophyll-retrieval algorithm for satellite imagery (Medium Resolution Imaging Spectrometer) of inland and coastal waters, J. Plankton Res., 24, 947-951, 2002.

Goody, R.: Atmospheric radiation 1, theoretical basis, Oxford University Press, 544 pp., 1964.

Gordon, H.: Atmospheric correction of ocean color imagery in the Earth Observing System era, J. Geophys. Res., 102, 1708117106, 1997.

Gordon, H., Clark, D., Brown, J., Brown, O., Evans, R., and Broenkow, W.: Phytoplankton pigment concentrations in the middle Atlantic bight: comparison of ship determinations and CZCS estimates, Appl. Optics, 22, 20-36, 1983.

Gordon, H., Brown, J., and Evans, R.: Exact Rayleigh scattering calculation for the use with the Nimbus-7 Coastal Zone Color Scanner, Appl. Optics, 27, 862-871, 1988a.

Gordon, H., Brown, O., Evans, R., Brown, J., Smith, R., Baker, K., and Clark, D.: A semianalytical radiance model of ocean color, J. Geophys. Res., 93(D9), 10909-10924, 1988b.

Hakvoort, H.: Absorption of light by surface water, Ph.d., Technische Universiteit, Delft, 1994.

Hakvoort, H., de Haan, J., Jordans, R., Vos, R., Peters, S., and Rijkeboer, M.: Towards airborne remote sensing of water quality in The Netherlands - validation and error analysis, ISPRS J. Photogramm., 57, 171-183, 2002.

Hoge, F. E. and Lyon, P. E.: Satellite retrieval of inherent optical properties by linear matrix inversion of ocean radiance models: An analysis of model and radiance measurement errors, J. Geophys. Res., 101, 16631-16648, 1996.

Hoogenboom, H., Dekker, A., and De Haan, J.: Retrieval of chlorophyll a and suspended matter in inland waters from Casi data by matrix inversion, Can. J. Remote Sens., 24, 144-152, 1998.

Kallio, K., Kutser, T., Hannonen, T., Koponen, S., Pulliainen, J., Vepsalainen, J., and Pyhalahti, T.: Retrieval of water quality from airborne imaging spectrometry of various lake types in different seasons, Sci. Total Environ., 208, 59-77, 2001.

Kishino, M., Tanaka, A., and Ishizaka, J.: Retrieval of Chlorophyll a, suspended solids, and colored dissolved organic matter in Tokyo Bay using ASTER data, Remote Sens. Environ., 99, 66-74, 2005.

Kopelevich, O.: Small-parameter model of optical properties of sea waters, Vol. 1, Physical Ocean Optics, Nauka, 1983.

Laws, E.: Mathematical Methods for Oceanographers: An introduction, John Wiley and Sons, New York, 343 pp., 1997.

Lee, Z. and Carder, K.: Hyperspctral remote sensing, in: Remote Sensing of Coastal Aquatic Environments, edited by: Miller, R., del Castillo, C., and McKee, B., Springer, Dordrecht, The Netherlands, 181-204, 2005.

Lee, Z.: Remote sensing of inherent optical properties: Fundamentals, tests of algorithms, and applications, Tech. Rep. 5, International Ocean-Colour Coordinating Group, 2006. 
Lee, Z., Carder, K., Mobley, C., Steward, R., and Patch, J.: Hyperspectral remote sensing for shallow waters: 2. Deriving bottom depths and water properties by optimization, Appl. Optics, 38, 3831-3843, 1999.

Malkmus, W.: Random Lorentz band model with exponential-tailed $\mathrm{S}^{-1}$ line intensity distribution function, J. Opt. Soc. Am., 57, 323-329, 1967.

Maritorena, S. and Siegel, D.: Consistent merging of satellite ocean color data sets using a bio-optical model, Remote Sens. Environ., 94, 429-440, 2005.

Maritorena, S., Siegel, D., and Peterson, A.: Optimization of a semianalytical ocean color model for global-scale applications, Appl. Optics, 41, 2705-2714, 2002.

Mobley, C.: Light and water radiative transfer in natural waters, Academic Press, 592 pp., 1994.

Petzold, T.: Volume scattering functions for selected ocean waters, in: Light in the Sea, edited by: Tyler, J., Dowden, Hutchinson and Ross, Stroudsburg, Pa. USA, Vol. 12, pp. 150-174, 1977.

Pop, R. and Fry, E.: Absorption spectrum (380-700 nm) of pure water: II, Integrating cavity measurements, Appl. Optics, 36, 8710 8723, 1997.

Press, W., Teukolsky, S., Vetterling, W., and Flannery, B.: Numerical recipes in $\mathrm{C}++$, The art of scientific computing, Cambridge University Press, 1002 pp., 2002.

Salama, M. S.: Optical remote sensing for the estimation of marine bio-geophysical quantities, Ph.D. Thesis, Katholieke Universiteit, Leuven, 2003.

Salama, M. S., Monbaliu , J., Coppin, P.: Atmospheric correction of Advanced Very High Resolution Radiometer imagery, Int. J. Remote Sens., 25, 7/8, 1349-1355, 2004.

Shen, F., Salama, M. S., Zhou, Y., Li, J., Su, Z., and Kuang, D.: Remote-sensing reflectance characteristics of highly turbid estuarine waters - a comparative experiment of the Yangtze River and the Yellow River, Int. J. Remote Sens., in press, 2009.
Schroeder, T., Behnert, I., Schaale, R., Fischer, J., and Doerffer, R.: Atmospheric correction algorithm for MERIS above case-2 waters, Int. J. Remote Sens., 28, 7, 1469-1486, 2007.

Su, Z., Timmermans, W. J., van der Tol, C., Dost, R., Bianchi, R., Gómez, J. A., House, A., Hajnsek, I., Menenti, M., Magliulo, V., Esposito, M., Haarbrink, R., Bosveld, F., Rothe, R., Baltink, H. K., Vekerdy, Z., Sobrino, J. A., Timmermans, J., van Laake, P., Salama, S., van der Kwast, H., Claassen, E., Stolk, A., Jia, L., Moors, E., Hartogensis, O., and Gillespie, A.: EAGLE 2006 Multi-purpose, multi-angle and multi-sensor in-situ and airborne campaigns over grassland and forest, Hydrol. Earth Syst. Sci., 13, 833-845, 2009, http://www.hydrol-earth-syst-sci.net/13/833/2009/.

Sydor, M., Gould, R., Arnone, R., Haltrin, V., and Goode, W. Uniqueness in remote sensing of the inherent optical properties of ocean water, Appl. Optics, 43, 2156-2162, 2004.

Timmermans, W., Dost, R., and Su, Z.: EAGLE 2006 - EAGLE Netherlands multi-purpose, multi-angle and multi-sensor in-situ, airborne and spaceborne campaigns over grassland and forest, Tech. rep., Department of Water Resources International Institute for Geo-Information Science and Earth Observation, ITC, 2007.

Van der Velde, R., Su, Z., and Ma, Y.: Impact of soil moisture dynamics on ASAR so signatures and its spatial variability observed over the Tibetan Plateau, Sensors, 8, 5479-5491, 2008.

Van der Woerd, H. and Pasterkamp, R.: HYDROPT: A fast and flexible method to retrieve chlorophyll- $a$ from multispectral satellite observations of optically complex coastal waters, Remote Sens. Environ., 112, 1795-1807, 2008.

Vermote, E., Tanre, D., Deuze, J., Herman, M., and Morcrette, J.: Second simulation of the satellite signal in the solar spectrum, 6S: An overview, IEEE T. Geosci. Remote, 35, 675-686, 1997.

Vos, R., Villars, M., Roozekrans, J., Peters, S., and Raaphorst, W. V.: Integrated monitoring of total suspended sediment in the Dutch coastal zone, Tech. rep., part II, 1998.

Wang, P., Boss, E., and Roesler, C.: Uncertainties of inherent optical properties obtained from semianalytical inversions of ocean color, Appl. Optics, 44, 4074-4084, 2005. 